\title{
Anatomical and biomechanical traits of broiler chickens across ontogeny. Part II. Body segment inertial properties and muscle architecture of the pelvic limb
}

In broiler chickens, genetic success for desired production traits is often shadowed by welfare concerns related to musculoskeletal health. Whilst these concerns are clear, a viable solution is still elusive. Part of the solution lies in knowing how anatomical changes in afflicted body systems that occur across ontogeny influence standing and moving. Here, to demonstrate these changes we quantify the segment inertial properties of the whole body, trunk (legs removed) and the right pelvic limb segments of five broilers at three different age groups across development. We also consider how muscle architecture (mass, fascicle length and other properties related to mechanics) changes for selected muscles of the pelvic limb. All broilers used had no observed lameness, but we document the limb pathologies identified post mortem, since these two factors do not always correlate, as shown here. The most common leg disorders, including bacterial chondronecrosis with osteomyelitis and rotational and angular deformities of the lower limb, were observed in chickens at all developmental stages. Whole limb morphology is not uniform relative to body size, with broilers obtaining large thighs and feet between four and six weeks of age. This implies that the energetic cost of swinging the limbs is markedly increased across this growth period, perhaps contributing to reduced activity levels. Hindlimb bone length does not change during this period, which may be advantageous for increased stability despite the increased energetic costs. Increased pectoral muscle growth appears to move the centre of mass cranio-dorsally in the last two weeks of growth. This has direct consequences for locomotion (potentially greater limb muscle stresses during standing and moving). Our study is the first to measure these changes in the musculoskeletal system across growth in chickens, and reveals how artificially selected changes of the morphology of the pectoral apparatus may cause deficits in locomotion. 


\section{TITLE:}

2 Anatomical and biomechanical traits of broiler chickens across ontogeny. Part II. Body segment

3 inertial properties and muscle architecture of the pelvic limb

4

\section{AUTHORS:}

6 Heather Paxton ${ }^{1}$, Peter G. Tickle ${ }^{2}$, Jeffery W. Rankin ${ }^{1}$, Jonathan R. Codd ${ }^{2}$ and John R.

7 Hutchinson $^{1}$

\section{AFFILIATIONS:}

$10{ }^{1}$ Structure \& Motion Laboratory, Department of Comparative Biomedical Sciences, The Royal

11 Veterinary College, University of London, Hatfield, Hertfordshire, UK

$12{ }^{2}$ Faculty of Life Sciences, University of Manchester, Manchester, UK

\section{CORRESPONDING AUTHOR:}

15 Heather Paxton, Structure \& Motion Laboratory, Department of Comparative Biomedical

16 Sciences, The Royal Veterinary College, University of London, Hatfield, Hertfordshire, UK, +44

17 (0) 1707666 422, hpaxton@,rvc.ac.uk 


\section{INTRODUCTION:}

The poultry industry is a rapidly expanding enterprise (over 870 million broilers

slaughtered in the UK; DEFRA 2013 statistics), in which production continues to increase globally by over $130 \%$ in some countries (Scanes 2007). In addition to increased production, the broiler chicken has gained an unusual repertoire of anatomical traits, which are repeatedly emphasized in scientific studies and highlight what has developed into a successful breeding programme for obtaining desired production characteristics (e.g. Havenstein et al., 2003; Paxton et al., 2010, 2013). However, a crossroads has been reached where efficient broiler production is haunted by welfare concerns (Julian, 1998; Mench, 2004; Knowles et al., 2008). Broilers may suffer from heart failure and sudden death syndrome (Julian, 1998; Maxwell and Robertson, 1998; Olkowski et al., 2007), reduced adaptive immune function (Cheema et al., 2003), leg weakness (see review; Bradshaw et al., 2002), poor reproductive performance (Siegel and Dunnington, 1987; Hocking, 1993) and appear to be susceptible to suboptimal management of nutrition and their environment (e.g. Vestergaard and Sanotra, 1999; Kestin et al., 2001; Scott, 2002; Brickett et al., 2007; Buijs et al., 2009). Unfortunately, whilst the welfare and economic concerns associated with these issues are clear, there is no optimal evidence-based solution that resolves all concerns surrounding broiler chicken production.

To move toward such a solution, a deeper understanding of how broiler body shape and musculoskeletal function develops during growth and how these changes may influence locomotion is required. Part 1 of this series (Tickle et al., MS) characterized how broiler organ and pectoral muscle growth varies with increasing body mass, with a focus on respiratory system development and changes in organ size, highlighting important repercussions to breathing/ cardiorespiratory performance. Here, we delve deeper into how these and other anatomical changes have affected the overall size and shape of the broiler and investigate how relevant traits have likely influenced their locomotor abilities.

To help achieve our aim, we detail the muscle architectural properties of the major pelvic limb muscles (identified previously by Paxton et al., 2010 as the hip, knee and ankle extensors in

62 broilers) and document how these scale with body size. Skeletal muscle is one of the organs that

63 is most adaptable to environmental change (Lieber, 1986), and an integral component of

64 locomotion (supporting and powering the movement). Muscle mechanical performance is mostly

65 dependent on a few key architectural properties; namely mass, fascicle length and pennation angle. These parameters are typically used to calculate physiological cross-sectional area (PCSA) 
67 and thereby estimate muscular capacity for force-generation (PCSA) versus length change

68 (fascicle length) (Powell et al., 1984; Burkholder et al., 1994; Lieber and Friden, 2000). For

69 broilers, muscle architecture data on the broiler currently exist for animals at six weeks of age

70 (see Paxton et al., 2010), but how these properties change across growth in the broiler is

71 unknown. This study therefore focuses on the scaling (i.e., size related, isometric or allometric;

72 Biewener, 1989; Alexander et al., 1981; Alexander and Ker, 1990) relationships of select pelvic

73 limb muscles to reveal changes in individual muscle characteristics of individual muscles from

74 hatching to slaughter age ( $\sim$ six weeks). We also consider how the pelvic limb bones (femur,

75 tibiotarsus and tarsometatarsus) scale with body size in the broiler chicken, as effective scaling of

76 the hindlimb bones can reduce the rate at which stress increases with body mass (McMahon,

77 1973, 1975; Garcia and da Silva, 2004).

78

In addition, differences in limb orientation and motion, and overall gait dynamics, among avian taxa can be partially attributed to variation in body centre of mass $(\mathrm{CoM})$ position (Gatesy and Biewener, 1991; Abourachid, 1993; Hutchinson, 2004). Manion (1984) estimated CoM position for chickens across ontogeny (5-19 days) and noted a cranioventral shift and a subsequent change in limb orientation during standing and walking (more flexed during standing, but more extended during walking). The broiler CoM position has been addressed in preliminary computational analyses by Allen et al., (2009) and was found to shift caudodorsally. Other previous research suggests that broilers have a more cranially positioned CoM induced by a large pectoral muscle mass (Abourachid, 1993; Corr el al., 2003a). To better understand the influence of CoM on locomotor ability in broilers, we therefore quantify the variation in CoM position (3D) across ontogeny and relate this variation to anatomical changes documented here and in Part I of this study (Tickle et al., MS).

All broilers used here are considered 'normal' -i.e. no observed lameness, but we

91 document the limb pathologies (identified post mortem) within our study populations. This is

92 essential, because the pathological changes in affected birds do not often relate to walking ability

93 (assessed using gait score and force plate measurements) (Sandiland et al., 2011). We quantify

94 the inertial properties (mass, centre of mass and radius of gyration) of each limb and major body

95 segment (Fig. 1), because these help reveal basic locomotor habits (e.g. limb tapering -i.e. a

96 proximal to distal reduction in muscle mass reflects a specialization for power versus force

97 development; Alexander et al., 1981; Pasi and Carrier, 2003; Hutchinson, 2004, Payne et al.,

98 2005a, 2005b; Smith et al., 2006). Both centre of mass position and radius of gyration are also

99 good descriptors of body area distribution and resistance to rotational movements (Kilbourne, 
100 2013). Importantly, inertial properties in chickens and more specifically broilers are almost

101 completely unstudied. Only a few studies have documented the inertial properties of other

102 ground running birds (e.g., emus, Goetz et al., 2008; guinea fowl, Daley et al., 2007; Rubenson

103 and Marsh, 2009; quail, Andrada et al., 2013; lapwing, Nyakatura et al., 2012). This study not

104 only provides a novel insight into characteristics that influence broiler locomotor function, but

105 also provides the inertial properties necessary to develop models for dynamic analyses of

106 movement, which have been highly successful in improving our understanding of human

107 pathological gait (e.g. Steel et al., 2012; Fey et al., 2013; Allen et al., 2013).

MATERIALS AND METHODS:

\section{Birds}

Fresh male cadavers of a commercial broiler strain at different ages (days 1, 13, 29, 32

112 and 40; Table 1) were used for the hind limb muscle analysis and then a further five broilers of

113 the same commercial strain at approximately 14, 28 and 42 days of age (2, 4 and 6 weeks old)

114 were used to calculate the centre of mass (CoM) of the whole body, trunk and the pelvic limb

115 segments --i.e. the thigh, drumstick, shank and foot (Fig. 1). Hatchlings (day 1) are not included

116 in these CoM data, since our focus is in later stages of their development when breast muscle

117 growth is more evident and leg health issues are apparent. These chickens had been previously

118 killed by cervical dislocation. Pelvic limb bone dimensions (femur, tibiotarsus and

119 tarsometatarsus) were also recorded at 2, 4 and 6 weeks of age. These data are from the same

120 chickens used in Part I (Tickle et al., MS), which focuses on anatomy of the musculoskeletal

121 respiratory apparatus and changes in body and organ size across ontogeny. As our data are cross-

122 sectional rather than longitudinal, this study approximates an ontogenetic analysis, via inference

123 from comparisons among individuals. All chickens were raised in a commercial setting under

124 similar management guidelines and were not outwardly influenced by a laboratory setting. Full

125 ethical approval for this experiment was granted by the RVC Ethics Committee (approval URN

126 No. 2008-0001) under a Home Office license.

\section{Pathology}

129 All birds were macroscopically evaluated to establish the incidence of leg pathologies

130 (marked as present/ absent unless otherwise stated; Table 2). Each chicken was examined for 131 bacterial chondronecrosis with osteomyelitis (BCO) in the femur and tibiotarsus, tibial 132 dyschondroplasia (TD), tibial rotation (RT) and valgus/varus deformities (VVD). Tibial rotation 
133 above $20^{\circ}$ was considered abnormal. Similar to other studies (e.g. Shim et al., 2012) VVD was

134 classified as mild, moderate or severe following the methods described by Leterrier and Nys 135 (1992).

\section{Muscle Architecture}

The left pelvic limb from each individual (refer to Table 1) was dissected, with fourteen specific muscle-tendon units (see Table 3 for muscle names and abbreviations) being identified and systematically removed. Muscles identified included the main hip, knee and ankle extensors, which are involved in limb support during the stance phase and have been shown to have either massive, short-fibred muscles favouring greater force-generating capacity or have long parallelfibred muscles for fast contraction (Paxton et al., 2010), as in many other terrestrial species. Architectural measurements taken included muscle mass $\left(M_{m}\right.$; tendon removed), which was measured on an electronic balance $( \pm 0.001 \mathrm{~g})$, muscle fascicle length $\left(L_{f} ; \pm 1 \mathrm{~mm}\right)$, and fibre pennation angle $(\theta)$, where appropriate $\left( \pm 1^{\circ}\right)$. In order to account for variation of fascicle length and pennation angle within a muscle, $L_{f}$ and $\theta$ were calculated as the mean of five measurements made across each muscle. Physiological cross-sectional area (PCSA) was calculated for each muscle (Eq. 1; Sacks and Roy, 1982) from these measurements according to the equation:

$$
\begin{gathered}
\rho L_{f} \dot{i}^{-1} \\
P C S A=M_{m} \cos \theta \dot{~}
\end{gathered}
$$
mammalian and avian muscle (Mendez and Keys, 1960; Paxton et al., 2010).

\section{Centre of Mass and Inertial Properties}

Computed tomography (CT) scans were acquired of five male bird cadavers from each

158 group. The cadavers were scanned with a GE Lightspeed 8-detector scanner at 100mA and 120

$159 \mathrm{kVp}$ X-ray beam intensity using a $1 \mathrm{~mm} \mathrm{CT}$ slice thickness. In order to minimise postural effects

160 on CoM estimates, the birds were placed in the same upright position with their left side resting 161 on a radiolucent cushion for scanning and limbs posed as similarly as possible (Fig. 1a). Mimics

16214.12 imaging software (Materialise; Leuven, Belgium) was then used to segment the resulting 163 DICOM image files, creating a 3D representation of the skeleton, body and the pelvic limb 164 segments (trunk, thigh, drumstick, shank and the foot; Fig. 1b). We used predefined thresholds 
165 set for bone and flesh, with some manual adjustment from those baseline values as appropriate to

166 ensure smooth, plausible rendering. Custom software (Hutchinson et al., 2007; Allen et al.,

167 2009)) was then used to estimate the whole body/ segment CoM. This method allows accurate

168 specification of the CoM relative to any user defined point on the body or segment. These points

169 are easily identified using bony landmarks visible on the CT images and are essential for putting

170 CoM position in the context of gross morphology, which is necessary for biomechanical analyses.

171 Using the 3D model representations of the skeleton, whole body CoM position was quantified

172 relative to the right hip, trunk CoM was taken relative to the pelvis (centre point between the hips

173 on the pelvis), and for the remaining segments, CoM position was expressed relative to the

174 proximal end of the bone (Fig. 2). Three-dimensional coordinates (x [craniocaudal], y

175 [dorsoventral] and $\mathrm{z}$ [mediolateral]) for the CoM were then recorded. Whole body CoM position

176 was expressed as a percentage of femur length (see Allen et al., 2009).

Segment anatomical properties that we measured and present here include segment mass

(m; as \% body mass), segment length (L; see Fig. 2), centre of mass (as \% segment length), and radius of gyration (r; as \% segment length), which are essential information required to calculate the moments of inertia $\left(\mathrm{kgm}^{2}\right.$; Eq. 3) and subsequently complete the set of inertial properties required for biomechanical analyses: moment of inertia (I) and mass of the segment, both estimated using the custom software. The mean difference between the dissected segment mass recorded and that estimated were small ( $<$ $5 \%$ ). These data also provide further information on muscle mass distribution within the limb.

$$
\mathrm{I}=\mathrm{m}(\mathrm{r} \mathrm{L})^{2}
$$

\section{Bone Scaling Dataset}

193 Data from Part I of this study were also used for this analysis. The individual bone

194 lengths of the left pelvic limb were recorded $( \pm 1 \mathrm{~mm})$ for each of four age groups: day $1(\mathrm{n}=10)$,

$195 \sim 14$ days $(\mathrm{n}=20), \sim 28$ days $(\mathrm{n}=19), \sim 42$ days $(\mathrm{n}=19)$. Total leg length was defined as the sum of

196 the individual pelvic limb bone lengths. Limb bone proportions were calculated as a percentage

197 of total leg length. 


\section{Statistical Analysis}

All of our analyses take into account differences in body size across age groups. To analyse the muscle architecture data, the linear relationship between log-transformed body mass and muscle mass, fascicle length and PCSA were examined using the reduced major-axis regression (RMA) function in the statistical program PAST (Hammer et al., 2001). RMA regression was appropriate for analysis of these morphological characters because error in both $\mathrm{x}$ and y variables is considered (Rayner, 1985; Sokal and Rohlf, 1995). Upper and lower 95\% confidence intervals (CIs) and the $\mathrm{R}^{2}$ value for each regression line were calculated to quantify the variation around the mean (Fig. 3, Table 4). Isometric scaling was assumed when the scaling exponent $\pm 95 \%$ CIs overlapped the expected value. Reduced major-axis regression was also used to examine the linear relationship between log-transformed body mass and bone length. This was done using custom Matlab (The Mathworks, Nattick, MA, USA) software code. The 95\% CIs and the $\mathrm{R}^{2}$ value for each regression line were also calculated (Fig. 4). Similar to the statistical analysis used for the muscle architecture data, isometric scaling was assumed when the scaling exponent $\pm 95 \%$ CIs overlapped the expected value.

For CoM values and segment anatomical properties, the statistics used followed those set out in Part I of this study. In brief, a Shapiro-Wilk normality test, in combination with considering subsequent PP and QQ plots of the data, and Levene's test for equal variances were used to test the assumptions of a one-way analysis of variance (ANOVA). An ANOVA test was then conducted with a subsequent Bonferroni post-hoc test to check for differences among the three age groups. If equal variances were violated, the Welch statistics are reported in conjunction with the results of a subsequent Games-Howell post-hoc test (Table 8).

\section{RESULTS:}

\section{Pathology}

224 There were a number of pathological changes in the study population at all stages of

225 development (see Table 2). Bacterial chondronecrosis with osteomyelitis (BCO) was present in

226 all populations both in the femur and proximal tibia. There was an increased incidence of BCO

227 in the femur as the broilers aged, with $88 \%$ of the six week old chickens affected. Tibial

228 dyschondroplasia was present in all populations with no apparent correlation with age (average

$22941 \%$ ). Rotated tibia was more prevalent in the younger birds ( $33 \%$ of the study population). 
230 Valgus angulation of the lower limb was seen only in the six-week old chickens, with

231 approximately $45 \%$ of these chickens affected. No varus deformities were observed.

Muscle architecture

Across ontogeny, the masses of the major hip, knee and ankle extensor muscles generally scale with positive allometry, increasing in relative size as broilers grew (Table 4). The exceptions were the FMTM (M. femorotibialis medialis), TCF (M. tibialis cranialis caput femorale), PIF (M. puboischiofemoralis) and IC (M. iliotibialis cranialis), which did not change significantly with body mass. Interestingly, fascicle length, in general, did not change with body mass, but scaled isometrically. However, the IL (M. iliotibialis lateralis) muscle showed an increase in fascicle length, whereas the GM (M. gastrocnemius medialis) showed a decrease in fascicle length. Despite these changes in fascicle length, PCSA appeared to increase allometrically across ontogeny in the majority of the pelvic limb muscles. The IC and TCF, however, scaled more in accordance with isometry.

\section{Whole Body Centre of Mass}

Whole body CoM moved caudodorsally until 28 days of age. By 42 days of age there was a significant cranial shift in CoM position, moving $\sim 10 \%$ cranially and $\sim 30 \%$ more dorsally in the last two weeks approaching slaughter age (Table 5).

\section{Segment Properties}

There was a 50-fold range in body mass of our sample of broiler chickens (Table 1), ranging from $\sim 0.04 \mathrm{~kg}$ at one day old to $\sim 2.4 \mathrm{~kg}$ at 40 days of age. Trunk mass contribution to whole body mass increased across ontogeny and was $\sim 5 \%$ larger at 42 days of age relative to the youngest group. Similarly, a significantly larger relative thigh muscle mass was found in older birds (by $\sim 3 \%$ body mass) compared to the younger broilers. Drumstick mass increased significantly with age whereas shank mass remained unchanged. Between 28 and 42 days, the chickens' foot mass also increased significantly by $230 \%$ (see Table 6).

Trunk CoM moved caudally between 28 and 42 days, and the thigh, drumstick and shank

259 CoM moved to more proximal positions (Table 5). In contrast, the foot's CoM moved more 260 distally at 42 days of age.

261 The radii of gyration about the axes of long-axis rotation (Table 6) experienced an

262 increase in the foot segments of the six week old broilers and remained unchanged in the thigh, 
263 drumstick and shank. However, the radius of gyration of the whole trunk segment showed a

264 decrease for long-axis rotation - i.e. a lower resistance to yaw. The radii of gyration in the

265 parasagittal plane, decreased in the drumstick and shank across broiler ontogeny, but

266 progressively increased in the foot. There was also a relative reduction of $r \%$ about the axis of

267 abduction/ adduction rotation. Radii of gyration for the thigh remained unchanged.

268

\section{Bone Scaling}

270

Tibiotarsus and tarsometatarsus length scaled isometrically with body mass, whereas femur length scaled with slight negative allometry (Fig. 4). As a result, there was a relative increase in total leg length from 14 days to 28 days. Limb length remained unchanged between four and six weeks. The femur accounts for $\sim 30 \%$ of total leg length and the tibiotarsus accounts for $\sim 41 \%$ of leg length. The tarsometatarsus is relatively shorter than the other pelvic limb bones accounting for $\sim 29 \%$ of total leg length.

\section{DISCUSSION}

The genetic success of the modern broiler and the subsequent changes to the morphology

of broiler chickens have been well documented, in order to determine the lines' commercial performance (e.g. Gous et al., 1999) and compare both growth responses and physiological adaptations resulting from distinctive selection pressures (e.g. Havenstein et al., 2003a, b;

Reddish and Lilburn, 2004; Schmidt et al., 2009). A marked change in total pectoral muscle mass of the commercial broiler is a common finding of all these prior studies. Similarly, we found this mass to represent $\sim 20 \%$ of total body mass in slaughter age chickens (see Part I; Tickle et al., MS). Part I revealed how enlarged pectoral muscle mass, among other anatomical changes, may compromise the efficacy of the respiratory apparatus. Here we show how these changes influence the locomotor ability of the broiler.

\section{Pathology}

Leg weakness in broilers comprises not only nonspecific gait problems and lower activity levels, but also a wide range of disorders that are generally classified as infectious, degenerative,

292 or developmental (for a review see Bradshaw et al., 2002). The most common disorders include

293 bacterial chondronecrosis with osteomyelitis (BCO), angular and torsional deformities (e.g.

294 valgus-varus (VVD) and rotated tibia (RT)) and tibial dyschondroplasia (TD). With the

295 exception of VVD, these conditions were observed in birds at all developmental stages in this 
study. $\mathrm{BCO}$ was common in the broilers (Table 2), far exceeding previous estimates of infection

297 in commercial flocks (approximately $0.5 \%$ ). Incidence of BCO in the femur peaked at $88 \%$ of

298 42-day-old birds. This variation is likely due to differences in how these estimates of infection were determined. Femoral head separation (FHS; epiphyseolysis) dominated in our study's birds,

300 which we concur should be attributed to underlying traumatic (osteochondrosis) or infectious (osteomyelitis) femoral head pathology (following Wideman et al., (2013)). FHS is often shown separately in studies to show the progression of the disease (e.g. Wideman et al., 2012; Wideman and Pevzner, 2012; Wideman et al., 2013), but here we are purely interested in the presence or absence of the condition. Furthermore, the high percentage of birds we found to have BCO may reflect a predisposition to the condition or differences in husbandry practices . Increasing occurrence of $\mathrm{BCO}$ over development is consistent with previous results that identified peak incidence at around five weeks of age (McNamee 1999a). Increasing incidence over development may reflect increased stresses acting on the bone, which are thought to contribute to BCO (Wideman, 2013). Similarly, BCO in the tibiotarsus was widespread and increased with age, showing a peak at 42 days (Table 2). BCO causes lesions in the load-bearing growth plates of the femur and tibiotarsus, so rapid growth and weight gain may be an aggravating factor when bacterial infection is present. Considering the widespread incidence of $\mathrm{BCO}$ in birds that were otherwise deemed healthy, bone lesions are a significant problem affecting welfare standards in broiler chickens.

TD commonly leads to growth plate abnormalities, infections and tibial deformation

316 (Lynch et al., 1992) but, similar to BCO, TD does not necessarily induce lameness of sufficient 317 severity to impair walking ability (Pattison, 1992). TD has been found to occur between 2 and 8 318 weeks of age and our findings are consistent with this observation (Table 2). However, 319 considerable variation exists in the reported prevalence of TD, ranging in 42 day old birds from 320 approximately $2 \%$ to $50 \%$ of total flock population. Incidence of TD in this study was relatively 321 high and occurred in all age groups, peaking at 28 days (57\%). However, determining why the 322 incidence of TD is high in this study is difficult because the condition reflects a complicated 323 interaction of contributing factors, including dietary deficiencies, toxins, genetic predisposition 324 and rapid growth rate .

325 Valgus-varus deformities (VVD) were observed in 42-day-old birds, but was not present 326 in younger broilers (Table 2). Comparable reports indicate that VVD occurs with varying 327 incidence, affecting as few as $0.5 \%$ to $30-40 \%$ of birds in a flock. The prevalence of VVD in 328 this study fell near the high end of the reported range, with $45 \%$ of birds at 42 days of age 
329 observed to have mild or moderate VVD. Our observation that symptoms of VVD occur only in

330 older broilers is consistent with the progressive nature of this deformity . However, no deformity

331 was seen in 28-day-old birds, which is perhaps surprising because this is approximately the age

332 that VVD often becomes prominent, although the timing of onset is known to vary .

333 Rotated Tibia (RT) occurred in birds at all developmental stages at a higher than expected

334 rate (i.e., value) compared to previous work (0.2\%, Bradshaw et al., 2002)). However, Bradshaw

335 et al., reported a reduced proportion of RT in older broilers, which perhaps indicates that affected

336 birds were culled because the condition becomes clearly obvious around 21 days of age. The

337 exact aetiology of RT is unknown; however TD and VVD may exacerbate the incidence of RT ,

338 thereby contributing to the relatively high proportion of birds with an outward torsion of the tibial 339 shaft.

340 Overall, there is a clear need to monitor the leg health of flocks, not only to aid breeders

341 to make adjustments to management practices or genetics when necessary, but also to quickly

342 identify lame birds for euthanasia on welfare grounds. The high incidence of leg pathologies

343 highlights the problem of maintaining high growth rates and breast muscle mass $\left(M_{\mathrm{b}}\right)$ at the

344 expense of broiler anatomy and physiology. In addition, lameness represents a significant

345 economic cost to the industry as birds with leg weakness are prematurely culled or have an

346 increased incidence of mortality (Mench, 2004). Efforts to improve the health of growing

347 broilers will have the twin benefit of improving both welfare standards and productivity.

\section{Muscle Architecture}

Architectural properties used to calculate the effective physiological cross-sectional area

351 (PCSA) (Gans and Bock, 1965) of muscle take into account the effect of pennate fascicles on

352 maximizing force per unit area. PCSA is thus greater in pennate muscles and is directly

353 proportional to its force generation capacity (Burkholder et al., 1994; Lieber and Friden, 2000).

354 In broilers, the PCSA of the major hip, knee and ankle extensors (essential for supporting body

355 mass and maintaining an upright standing posture; Gatesy 1999; Reilly, 2000; Hutchinson, 2004),

356 scale with positive allometry - i.e., these muscles have a greater force-generating capacity

357 (reflected in their relatively larger PCSAs) as the broiler develops (Table 4, Fig. 3). As a result,

358 muscular force production capacity in broiler chickens should increase with age, likely as a direct

359 consequence of weight vs. force scaling constraints imposed by resisting gravity and inertia (e.g.,

360 Corr et al., 2003). However, these muscles still have smaller force-generating capabilities and

361 shorter, presumably slower-contracting muscles than their wild counterpart, the Giant Junglefowl 
362 (Paxton et al., 2010). Broiler chickens appear to generally increase the PCSA of their pelvic limb 363 muscles by increasing muscle mass, rather than by increasing fascicle length, which scaled

364 isometrically (Table 4, Fig. 3). This increase in mass is likely due to increased hypertrophy

365 (increase in muscle fibre size), which is well known to occur in broiler skeletal muscle and is the 366 assumed dominant model for postnatal growth (Aberle and Stewart, 1983; Soike and Bergman,

367 1998; Remignon et al., 1994; Goldspink and Yang, 1999). In addition, muscular force production 368 is invariant to muscle fascicle length, but longer fascicles exact a metabolic cost because a larger 369 volume of muscle is activated for each Newton of force (Kram and Taylor, 1990; Roberts et al., 370 1998). Thus, the isometric scaling of fascicle length we observed in this study avoids such added 371 costs.

372 Interestingly, the PCSAs of the M. iliotibialis cranialis (IC) and M. tibialis cranialis caput 373 femorale (TCF) scale more in accordance with isometry. The relative force-generating capacity 374 of these muscles therefore remains unchanged throughout the growth of the broiler. The TCF is a 375 knee extensor and ankle flexor and is assisted by other muscles that also serve as knee extensors 376 and ankle flexors (e.g., M. femorotibialis and M. extensor digitorum longus). Similarly, the IC is 377 also a knee extensor, but additionally acts as a hip flexor, supported by the M. iliotrochantericus 378 caudalis (ITC; known to be significantly larger in the broiler [Paxton et al., 2010])) to flex and 379 medially rotate the femur. The additional support of these muscles may help to explain why the 380 IC and TCF scale in unusually isometric ways. The IC and TCF may be redundant, especially 381 when limb motion in these broilers is likely to be 1) knee-driven (e.g. Gatesy, 1999; Reilly, 2000; 382 Hutchinson and Allen, 2009), requiring action of the major knee flexors (M. iliofibularis,

383 M.flexor cruris lateralis), and 2) three-dimensional, demanding large supportive forces at the hip 384 for the considerable mediolateral forces they experience when they walk (Paxton et al., 2013).

385 However, biomechanical analyses of in vivo function are needed to test how much their function 386 alters with growth in broilers.

\section{Centre of Mass and Inertial Properties}

At the youngest age (14 days old) studied here, chickens' trunk mass accounted for $\sim 75 \%$ of total body mass. At slaughter weight (around 42 days of age), total trunk mass had increased to $\sim 80 \%$ total body mass. The $\sim 5 \%$ increase in trunk mass is largely attributable to pectoral

392 muscle growth, which occurred at a relatively faster rate than body mass (see Part I Tickle et al., 393 2014). 
395 bone mass combined) did not decrease during growth, accounting for $\sim 15 \%$ of total body mass at

396 slaughter age and thus representing a total 5\% body mass increase across ontogeny. The

397 proportion of bone mass contributing to total segment mass is likely small because the muscle to

398 bone ratio is known to be high in commercial broilers (Ganabadi et al., 2009). The increase in leg

399 mass was instead incurred by increases in drumstick and thigh muscle mass. Drumstick segment

400 mass increased across ontogeny, becoming relatively larger at each age category, whereas thigh

401 segment mass only had substantial changes during the last two weeks of growth (from $28-42$

402 days old). Thigh muscle mass increased by $3 \%$ of total body mass during this period. Changes

403 in thigh and drumstick segment mass are expected, as these segments yield the most meat and are

404 the most consumed portions (alongside breast meat) on the market (Broadbent et al., 1981).

405 However, the increase in hind limb segment mass is striking and comparable to a progenitor

406 population (total limb muscle mass $\sim 16 \%$ ) at the same approximate physiological mass and

407 indeed larger than its wild counterpart at the same age by $\sim 4 \%$ body mass (see Paxton et al.,

408 2010). Previous studies typically show an ontogenetic reduction in the investment of metabolic

409 resources towards pelvic limb muscle growth (e.g. Berri et al., 2007; Schmidt et al., 2009) and

410 the main drivers of selection in broiler chickens are still a greater yield of breast muscle mass and

411 a faster post-hatch growth rate (Arthur and Albers, 2003). Thus, changes in leg muscle mass may

412 not reflect a direct difference in selection pressures. However, a relative increase in hind limb

413 muscle mass may reflect a functional demand for larger hip and knee extensors to support their

414 increasing body mass. Corr et al., (2003a) studied two strains of birds (relaxed and selected)

415 raised on two different feeding regimes and suggested that the large pectoral muscle mass of the

416 broiler has displaced their CoM cranially. Similarly, Abourachid (1993) suggested that increased

417 stresses on the pelvic limbs of heavier broad-breasted turkeys were induced by a more cranially

418 positioned CoM. We found that broilers show a change in whole body CoM position consistent

419 with these previous findings, shifting from a caudodorsal to a craniodorsal location between 28

420 and 42 days of age, which would increase demand for muscular force production to balance it.

421 Interestingly, the centre of mass of the Giant Junglefowl (a representative progenitor population)

422 has been shown to move caudodorsally, not craniodorsally, across ontogeny. This cranial shift in

423 broilers may therefore be the direct result of increased pectoral muscle mass growth between four

424 and six weeks of age.

425 In all cases, the craniocaudal CoM location in broilers was far more cranial than previous

426 estimates. Allen et al., (2009) estimated CoM cranial position to be $\sim 38 \%$ of femur length, 
compared to the $70-90 \%$ femur length estimated in this study. On the other hand, dorsoventral

428

429

430

431

432

433

434

435

436

437

438

439

440

441

442

443

444

445

446

447

448

449

450

451

452

453

454

455

456

457

458

459

estimates broadly corresponded to literature values (Allen et al., 2009). The difference in

craniocaudal CoM position likely relates directly to pectoral muscle growth. The pectoral muscle mass of the broilers used in this study yielded an additional $\sim 4 \%$ of total body mass in comparison to the broilers used by Allen et al., (2009). One limitation of our study is that whole body CoM was normalized by femur length, which did scale with slight negative allometry (see discussion below). Using femur length may introduce a slight bias to our results, but normalization by other factors including total limb length have been shown to yield the same result (Allen et al., 2009).

There are also substantial changes in the distal segment of the pelvic limb between 28 and 42 days. Foot mass increases by $\sim 30 \%$ and foot CoM moves distally. Large feet may serve to improve the apparent stability reported in the broiler (e.g. Corr et al., 2003b) during the stance phase of gait. However, larger feet will influence the broiler's ability to accelerate and decelerate the limb during swing, which in turn can affect the metabolic cost of locomotion (Kilbourne, 2013; Kilbourne and Hoffman, 2013). Both an increase in mass and a more distal shift in the limb's mass distribution will effectively increase a limb's moment of inertia, (i.e., resistance to angular acceleration, Steudel, 1990; Wickler et al., 2004; Kilbourne and Hoffman, 2003). Broiler pelvic limbs would therefore require more metabolic energy to accelerate and decelerate them as the birds grow. However, the influence of mass is much smaller than the influence of the distribution of the mass (radii of gyration reported here) on the moment of inertia. Doubling mass would essentially double the moment of inertia, whereas doubling the radii of gyration would increase the moment of inertia four-fold (Eq. 3). The radii of gyration in the parasagittal plane and about the axes of long-axis rotation increased in the foot segments of the $\sim 2$ day old broiler. Thus, increased radii of gyration in the foot segment of the broiler contribute significantly to the limb's moment of inertia.

We found that broilers' whole pelvic limb morphology changed across ontogeny, with the main changes in the thigh and foot segments. These segments had increased muscle mass and a more distal mass distribution (rather than having relatively longer limbs; see bone scaling discussion), resulting in relatively larger moments of inertia. The changes in limb morphology are likely to assist in supporting the increased supportive forces required by a more cranially positioned CoM and to help improve stability during locomotion. However, these changes also likely exact a relatively higher metabolic cost to locomotion. 


\section{Bone Scaling}

We have shown that femur length scaled with slight negative allometry, whereas the

462 lengths of the tibiotarsus and tarsometatarsus scale with isometry across broiler ontogeny (Fig. 4).

463 Regardless, total relative limb length remained unchanged from four to six weeks in growing

464 broilers may be an adaptation related to their apparent instability (Paxton et al., 2013).

465 Maintaining shorter limbs may act to moderate the lateral motion of the CoM and aid balance

466 (Bauby and Kuo, 2000). However, short limbs also likely lead to an increased energetic cost

467 (Steudel-Numbers and Tilken, 2004).

468 Here we have considered how pelvic limb morphology changes during broiler ontogeny,

469 in coordination with other changes such as pectoral muscle mass. Together, these changes have

470 influenced broiler morphology across ontogeny, which may have influenced locomotor ability as

471 well. The relative force-generating capacity of the hind limb muscles is greater in older broilers,

472 and is primarily achieved through increasing muscle mass but maintaining a constant fascicle

473 length. Increases in thigh segment mass and a relative increase in the moment of inertia of the

474 distal limb (due mainly to increased foot size) may reflect adaptations to cope with the apparent

475 instability and a more cranially positioned $\mathrm{CoM}$ as broilers grow. Although the architectural

476 changes we have observed have obvious advantages for maintaining an upright posture and

477 forward progression of broiler chickens, these morphological changes likely have a negative

478 impact on locomotion, exacting relatively higher metabolic costs during growth, which may have

479 knock-on consequences for activity levels and even overall health.

ACKNOWLEDGEMENTS

We would like to thank Cobb-Vantress, Inc, especially Kate Barger and Antony Taylor for providing the chickens used in this study.

\section{REFERENCES:}

Aberle ED, Stewart TS (1983) Growth of fiber types and apparent fiber number in skeletal muscle of broiler-type and layer-type chickens. Growth 47, 135-144.

Abourachid A (1993) Mechanics of standing in birds: functional explanation of lameness problems in giant turkeys. Br Poult Sci 34, 887-898. 
492 Alexander RM, Jayes AS, Maloiy GMO, Wathuta EM (1981). Allometry of the leg muscles 493 of mammals. J Zool 194, 539-552.

Alexander R, Ker R (1990) The architecture of leg muscles. In: Winters J, Woo S, editors. Multiple Muscle Systems: Biomechanics and Movement Organization. Berlin: Springer; pp. 568497 577.

Allen JL, Kautz SA, Neptune RR (2013) The influence of merged muscle excitation modules on post-stroke hemiparetic walking performance. Clin Biomech 28(6), 697-704.

Allen V, Paxton H, Hutchinson JR (2009) Variation in center of mass estimates for extant sauropsids, and its importance for reconstructing inertial properties of extinct archosaurs. Anat $\operatorname{Rec} 292,1442-1461$.

Andrada E, Nyakatura JA, Bergmann, F, Blickhan R (2013) Adjustments of global and 507 hindlimb local properties during the terrestrial locomotion of the common quail (Coturnix coturnix). J Exp Biol 216, 3906-3916.

Arthur JA, Alburs GAA (2003) Industrial perspective on problems and issues associated with 511 poultry breeding. In: Poultry Genetics, Breeding and Biotechnology, CABI Publishing Co., 512 Wallingford, UK.

514 Bauby CE, Kuo AD (2000) Active control of lateral balance in human walking. J Biomech 33, 515 1433-1440.

Berri C, Bihan-Duval EL, Debut M, Sante-Lhoutellier V, Baeza E, Gigaud V, Jego Y, Duclos

518 MJ (2007) Consequence of muscle hypertrophy on characteristics of pectoralis major muscle and 519 breast meat quality of broiler chickens. J Anim Sci 85, 2005-2011.

Biewener AA (1989) Mammalian terrestrial locomotion and size: mechanical design principles 522 define limits. Bioscience 39, 776-783. 
524 Bradshaw RH, Kirkden RD, Broom DM (2002) A review of the aetiology and pathology of leg

525 weakness in broilers in relation to their welfare. Avian Poult Biol Rev 13, 45-103.

527 Brickett KE, Dahiya JP, Classen HL, Gomis S (2007) Influence of dietary nutrient density,

528 feed form, and lighting on growth and meat yield of broiler chickens. Poult Sci 86, 2172-2181.

530 Broadbent, L. A., B. J. Wilson and C. Fisher (1981) The composition of the broiler chicken at 53156 days of age: output, components and chemical composition. Br Poult Sci 22, 385-390

533 Buijs S, Keeling L, Rettenbacher S, Van Pouke E, Tuyttens FAM (2009) Stocking density 534 effects on broiler welfare: identifying sensitive ranges for different indicators. Poult Sci 88, 535 1536-1543.

Burkholder TJ, Fingado B, Baron S, Lieber RL (1994) Relationship between muscle fiber types and sizes and muscle architectural properties in the mouse hindlimb. J Morph 221, 177190.

Cheema MA, Qureshi MA, Havenstein GB (2003) A comparison of the immune response of a 2001 commercial broiler with a 1957 random bred broiler strain when fed representative 1957 and 2001 broiler diets. Poult Sci 82, 1519-1529.

Corr SA, Gentle MJ, McCorquodale CC, Bennett D (2003a) The effect of morphology on the musculoskeletal system of the modern broiler. Anim Welfare 12, 145-157.

Corr SA, Gentle MJ, McCorquodale CC, Bennett D (2003b) The effect of morphology on walking ability in the modern broiler: a gait analysis study. Anim Welfare 12, 159-171.

Daley MA, Felix G, Biewener AA (2007) Running stability is enhanced by a proximo-distal gradient in joint neurmechanical control. J Exp Biol 210, 383-394

554 Fey NP, Klute GK, Neptune RR (2013) ASB Journal of Biomechanics Award - Altering 555 prosthetic foot stiffness influences foot and muscle function during below-knee amputee walking: 556 a modeling and simulation analysis. J Biomech 46(4), 637-644. 
558 Ganabadi S, Mutuviren S, Hilmi MA, Babjee SMA, Yaakub H, Fakurazi S (2009) Carcass

559 Composition of Jungle Fowl in Comparison with Broilers and Indigenous Chicken. Asian J Anim 560 Sci 3, 13-17.

561

562 Gans C, Bock WJ (1965) The functional significance of muscle architecture - a theoretical 563 analysis. Ergeb Anat Entwicklungsgesch 38, 115-142.

Garcia GJM, da Silva JKL (2004) On the scaling of mammalian long bones. J Exp Biol 207, 566 1577-1584.

Gatesy SM (1999) Guineafowl hind limb function I: cineradiographic analysis and speed effects.

J Morph 240, 127-142.

Gatesy SM, Biewener AA (1991) Bipedal locomotion: effects of speed, size and limb posture in birds and humans. J Zool 224, 127-147.

Goetz, JE, Derrick, TR, Pedersen, DR, Robinson, DA, Conzemius, MG, Baer, TE, Brown, TD (2008) Hip joint contact force in the emu (Dromaius novaehollandiae) during normal level walking. J. Biomech 41, 770-778.

Goldspink G, Yang SY (1999) Muscle structure, development and growth. In: Poultry Meat

Gous RM, Moran ET, Stilborn HR, Bradford GD, Emmans GC (1999) Evaluation of the parameters needed to describe the overall growth, the chemical growth, and the growth of feathers and breast muscles of broilers. Poult Sci 78, 812-821.

Havenstein GB, Ferket PR, Qureshi MA (2003) Growth, livability and feed conversion of 5861957 versus 2001 broilers when fed representative 1957 and 2001 broiler diets. Poult Sci 82, $587 \quad 1500-1508$. 
Hester PY, Ferket PR (1998) Relationship between long bone distortion and tibial dyschondroplasia in male turkeys. Poult Sci 77, 1300-1302.

591

Hocking PM (1993) Effects of body-weight at sexual maturity and the degree and age of 593 restriction during rearing on the ovarian follicular hierarchy of broiler breeder females. Brit Poult Sci 34, 777-784.

Hutchinson JR (2004). Biomechanical modeling and sensitivity analysis of bipedal running 597 ability I. extant taxa. $J$ Morph 262, 421-440.

Hutchinson JR, Ng-Thow-Hing V, Anderson FC (2007) A 3D interactive method for estimating body segmental parameters in animals: application to the turning and running performance of Tyrannosaurus rex. J Theor Biol 46, 660-680.

602

Julian RJ (1984) Valgus-varus deformity of the intertarsal joint in broiler chickens. Can Vet J 604 25, 254-258.

Julian RJ (1998) Rapid growth problems: ascites and skeletal deformities in broilers. Poult Sci 607 77, 1773-1780.

Julian RJ (2005) Production and growth related disorders and other metabolic diseases of 610 poultry - a review. Vet $J 169,350-369$.

611

612 Kestin SC, Gordon S, Su G, Sorenson P (2001) Relationships in broiler chickens between 613 lameness, liveweight, growth rate and age. Vet Rec 148, 195-197.

615 Kilbourne BM (2013) On birds: scale effects in the neognath hindlimb and differences in the 616 gross morphology of wings and hindlimbs. Biol J Linn Soc 110, 14-31.

618 Kilborn BM, Hoffman LC (2013) Scale effects between body size and limb design in 619 quadrupedal animals. PLoS ONE 8, e78392. 
621 Knowles TG, Kestin SC, Haslam SM, Brown SN, Green LE, Butterworth A, Pope SJ,

622 Pfeiffer D, Nicol CJ (2008) Leg disorders in broiler chickens: Prevalence, risk factors and 623 prevention. PLOS ONE 3, e1545.

624

625 Kram R, Taylor CR (1990) Energetics of running: A new perspective. Nature 346, 265-266.

626

627 Leterrier C, Nys Y (1992) Clinical and anatomical differences in varus and valgus deformities of 628 chick limbs suggest different aetio-pathogenesis. Avian Pathol 21, 429-442.

Lieber RL (1986) Skeletal muscle adaptability- Review of basic properties. Dev Med Child 631 Neurol 28, 390-397.

Lieber RL, Friden J (2000) Functional and clinical significance of skeletal muscle architecture.

634 Muscle Nerve 23, 1647-1666.

Lynch M, Thorp BM, Whitehead CC (1992) Avian tibial dyschondroplasia as a cause of bone deformity. Avian Pathol 21, 275-285.

Manion B L (1984). The effects of size and growth on hindlimb locomotion in the chicken. $P h D$ thesis. Univ. Illinois

Maxwell MH, Robertson GW (1998) UK survey of broiler ascites and sudden death syndromes 643 in 1993. B Poult Sci 39, 203-215.

McMahon, T (1973). Size and shape in biology. Science 179, 1201-1204.

McMahon, TA (1975) Using body size to understand the structural design of animals: 648 Quadrupedal locomotion. J Appl Physiol 39, 619-627.

Nyakatura JA, Andrada E, Grimm N, Weise H, Fischer MS (2012) Kinematics and center of mass mechanics during terrestrial locomotion in northern lapwings (Vanellus vanellus, Charadriiformes). J Exp Zool A Ecol Genet Physiol 317, 580-594. 
654 Pasi BM, Carrier DR (2003) Functional trade-offs in the limb muscles of dogs selected for 655 running vs. fighting. J Evol Biol 16, 324-332.

McNamee PT, McCullagh JJ, O’Hagan J, Spratt-Davidson, S, Mulholland EJ, Ball HJ, 658 Smyth JA (1999) A longitudinal study of leg weakness in five commercial broiler flocks. In: 659 Proceedings of the 48th Western Poultry Disease Conference, Canada.

McNamee PT, Smyth JA (2000) Bacterial chondronecrosis with osteomyelitis ('femoral head 662 necrosis') of broiler chickens: a review. Avian Pathol 29, 253-270.

D, Smyth JA (1998) Study of leg weakness in two commercial broiler flocks. Vet Rec 143, 131666135.

Mench JA (2004) Lameness. In: Measuring and Auditing Broiler Welfare. CABI, Wallingford, 669 UK.

Mendez J, Keys A (1960) Density and composition of mammalian muscle. Metabolism 9, 184672188.

Olkowski AA (2007) Pathophysiology of heart failure in broiler chickens: Structural, biochemical, and molecular characteristics. Poult Sci 86, 999-1005.

Orth MW, Cook ME (1994) Avian tibial dyschondroplasia: a morphological and biochemical review of the growth plate lesion and its causes. Vet Pathol 31, 403-404.

Pattison M (1992) Impacts of bone problems on the poultry meat industry. In: Bone Biology and 681 Skeletal Disorders in Poultry, Carfax Publishing Co., Abingdon. 
687 Paxton H, Daley MA, Corr SA, Hutchinson, JR (2013) the gait dynamics of the modern broiler 688 chicken: A cautionary tale of selective breeding. J Exp Biol 216, 3237-3248.

690 Payne RC, Hutchinson JR, Robilliard JJ, Wilson AM (2005) Functional specialisation of the 691 equine pelvic limb. J Anat 206, 557-574.

692

693 Powell, PL, Roy RR, Kanim P, Bello MA, Edgerton VR (1984) Predictability of skeletal 694 muscle tension from architectural determinations in guinea pig hindlimbs. Am Physiol Soc, 17156951721.

Prasad S, Hairr WT, Dallas JT (1972) Observations of abnormal cartilage formation associated with leg weakness in commercial broilers. Avian Dis 16, 457-461.

Randall CJ, Mills CPJ (1981) Observations on leg deformity in broilers with particular reference to the intertarsal joint. Avian Pathol 10, 407-431.

Rayner, JMV (1985) Linear relationships in biomechanics: The statistics of scaling functions. $J$ Zool Series A, 206, 415-439.

Reddish JM, Lilburn MS (2004) A comparison of growth and development patterns in diverse genotypes of broilers. 1. Male broiler growth. Poult Sci 83, 1067-1071.

Reilly SM (2000) Locomotion in the quail (coturnix japonica): the kinematics of walking and increasing speed. J Morph 243, 173-185.

Remignon H, Lefaucheur L, Blum JC, Ricard FH (1994) Effects of divergent selection for body weight on three skeletal muscles characteristics in the chicken. Br Poult Sci 35, 65-76.

Riddell C, Springer R (1985) An epizootiological study of acute death syndrome and leg weakness in broiler chickens in western Canada. Avian Dis 29, 90-102. running mechanics. J Exp Biol 201, 2753-2762. 
721 Rubenson, J, Marsh, RL (2009) Mechanical efficiency of limb swing during walking and 722 running in guinea fowl (Numida meleagris). J Appl Physiol 106, 1618 - 1630.

724 Sacks RD, Roy RR (1982) Architecture of the hindlimb muscles of cats: functional significance. $725 J$ Morph 173, 185-195.

Sandilands V, Brocklehurst S, Sparks N, Baker L, McGovern R, Thorp B, Pearson D (2011)

Assessing leg health in chickens using a force plate and gait scoring: how many birds is enough? 729 Vet Rec 168, 77.

730

Sauveur, B, Mongin, P (1978) Tibial dyschondroplasia, a cartilage abnormality in poultry. Ann

Biol Anim Biochim Biophys 18, 87-98.

733

734

Scanes CG (2007) The Global Importance of Poultry. Poult Sci 86, 1057-1058.

Schmidt CJ, Persia ME, Feierstein E, Kingham B, Saylor WW (2009) Comparison of a modern broiler line and a heritage line unselected since the 1950s. Poult Sci 88, 2610-2619.

Scott TA (2002) Evaluation of lighting programs, diet density, and short-term use of mash as compared to crumbled starter to reduce incidence of sudden death syndrome in broiler chicks to 35 days of age. Can J Anim Sci 82, 375-383. of growth rate on leg morphology and tibia breaking strength, mineral density, mineral content, and bone ash in broilers. Poult Sci 91, 1790-1795.

Siegel PB, Dunnington EA (1987) Selection for growth in chickens. Crit Rev Poult Biol 1, 1748 24. 
752 Smith NC, Wilson AM, Jespers KJ, Payne RC (2006). Muscle architecture and functional

753 anatomy of the pelvic limb of the Ostrich (Struthio camelus). J Anat 209(6), 765-79.

754

755 Steel KM, Van der Krogt MM, Schwartz MH, Delp SL (2012) How much muscle strength is

756 required to walkin in a crouch gait? J Biomech 45(15), 2564-2569.

757

758 Steudel-Numbers KL, Tilken, MJ (2004) The effect of lower limb length on the energetic cost 759 of locomotion: implications for fossil hominins. J Hum Evol, 47(1-2), 95-109.

Soike D, Bergmann V (1998) Comparisons of skeletal muscle characteristics in chicken bred for meat or egg production 1. Histopathological and electron microscopic examination. $J$ Vet Med 45, 764 161-167.

Steudel, K (1990). The work and energetic cost of locomotion. II. Partitioning

the cost of internal and external work within a species. J Exp Biol 154,

768 287-303.

Vaiano SA, Azuolas JK, Parkinson GB (1994) Serum total calcium, phosphorus, 1,25

Dihydroxycholecalciferol, and endochondral ossification defects in comercial broiler chickens

Vestergaard KS, Sanotra GS (1999) Relationships between leg disorders and changes in the behaviour of broiler chickens. Vet Rec 144, 205-209.

Wickler SJ, Hoyt DF, Clayton HM, Mullineaux DR, Cogger EA, Sandoval E, McGuire R, 36, 772-777.

Wideman R F, Pevzner I (2012) Dexamethasone triggers lameness associated with necrosis of the proximal tibial head and proximal femoral head in broilers. Poult. Sci.91, 2464-2474 
784 Wideman R F Jr, Hamal KR, Stark JM, Blankenship J, Lester H, Mitchell KN (2012) A

785 wire-flooring model for inducing lameness in broilers: Evaluation of probiotics as a prophylactic

786 treatment. Poult Sci 91, 870-883

787

788 Wideman RF Jr, Al-Rubaye A, Gilley A, Reynolds D, Lester H, Yoho D, Hughes JM,

789 Pevzner I (2013) Susceptibility of 4 commercial broiler crosses to lameness attributable to

790 bacterial chondronecrosis with osteomyelitis. Poult Sci 92, 2311-2325.

791 


\section{Figure 1}

Figure 1 - A 3D model representation of the broiler showing the body and pelvic limb segments.

Fig. 1 shows the 3D model representation of the broiler's body and its corresponding segments created within MIMICS software. Each chicken was placed in the same upright position with their left side resting on a radiolucent cushion during scanning. Fig. 1a shows the whole body and skeleton produced within this software and Fig. 1b shows the trunk (leg flesh removed) and pelvic limb segments. The translucent outline represents the 'virtual flesh' of the models used to estimate the inertial properties (mass, centre of mass and radius of gyration)of each segment.

a)

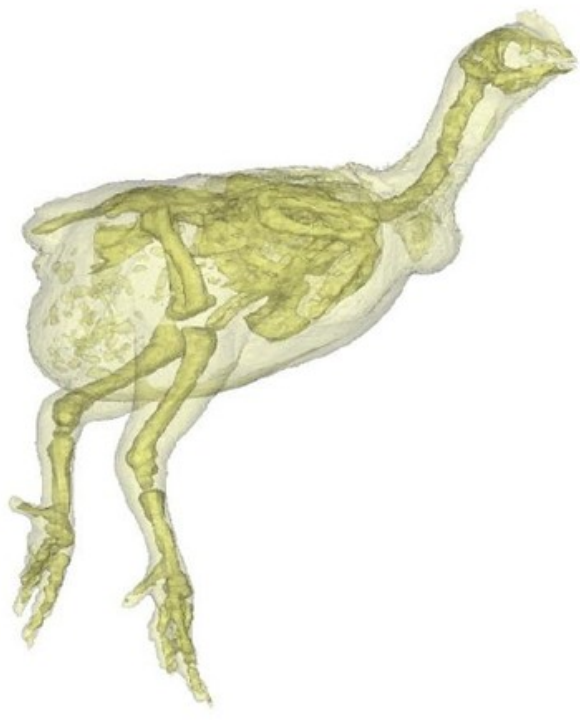

b)

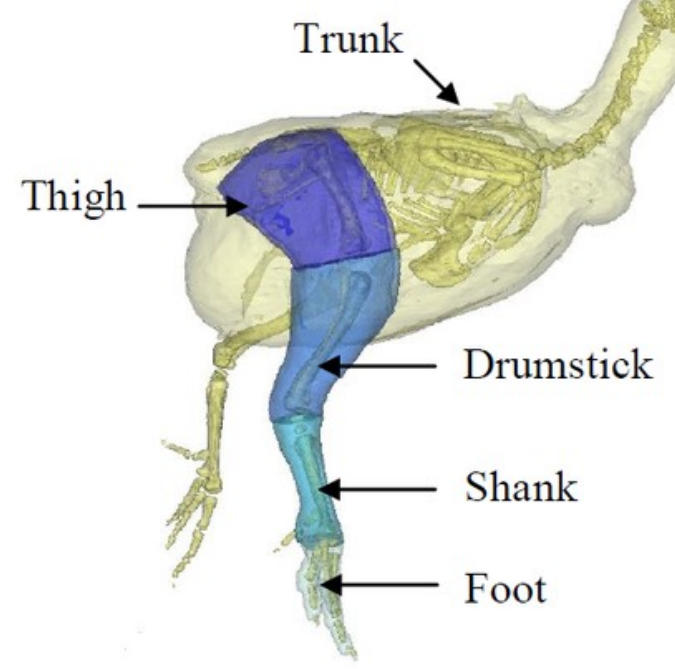




\section{Figure 2}

\section{Figure 2 - Segment inertial properties}

The pelvis, femur, tibiotarsus, tarsometatarsus and the bones of the foot are highlighted in this 3D model. Centre of mass (CoM) position is shown (black/ white circle; approximate position given). Trunk CoM was taken relative to the pelvis (centre point between the hips on the pelvis), and for the remaining segments, CoM positionwas expressed relative to the proximal end of the bone (red markers shown). The local anatomical coordinate system for each segment is given ( $x$ (red), y (green) and $z$ (blue)). Segment length (excluding the pelvis) is defined as the distance between the proximal and distal marker on the segment, as shown. 


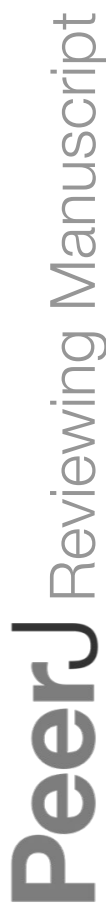

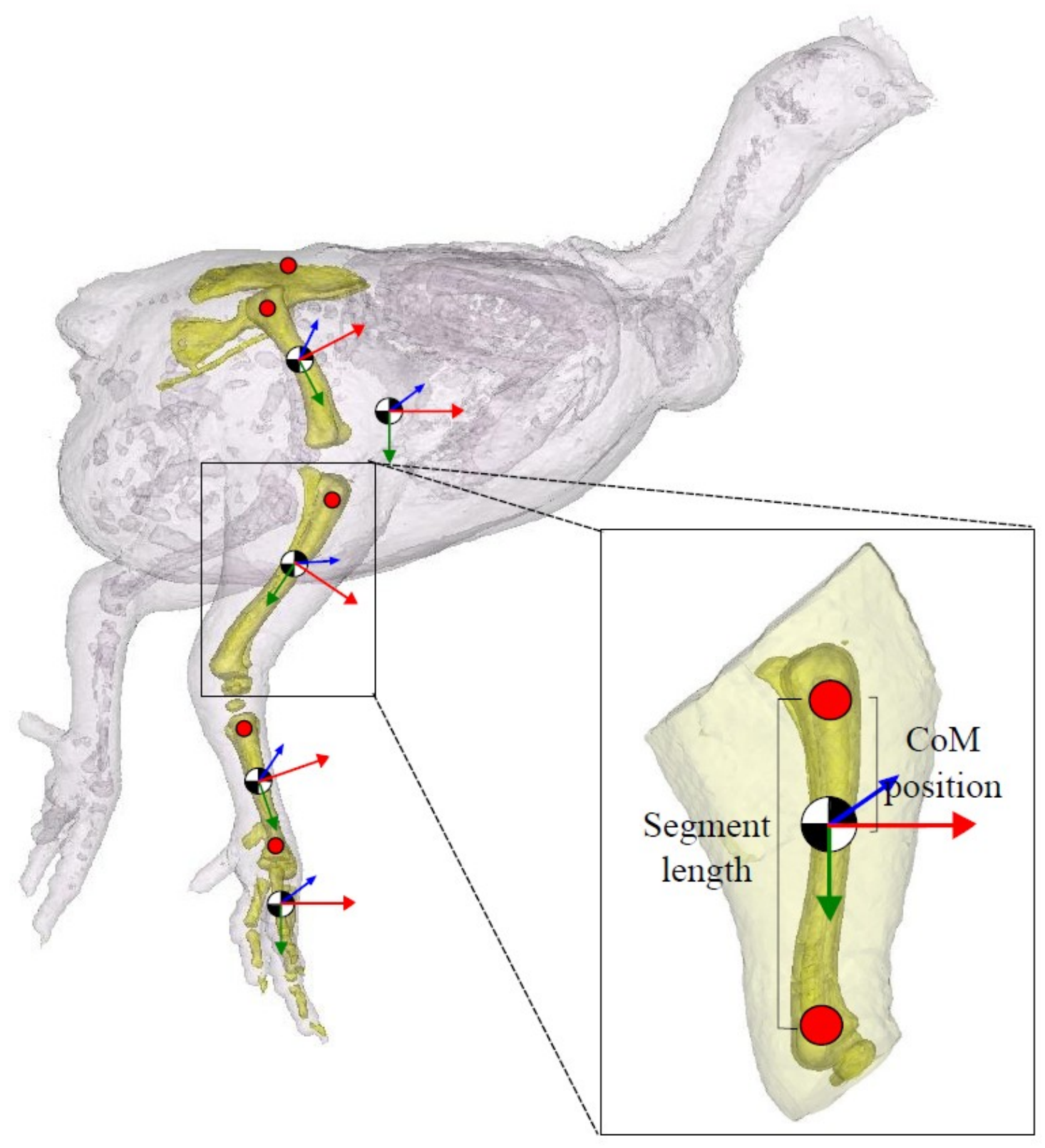




\section{Figure 3}

Figure 3 - Scaling exponents of pelvic limb muscle properties as a function of increasing body mass

Symbols indicate the regression slope for muscle mass (squares), physiological crosssectional area (PCSA; triangles) and muscle fascicle length (circles). Error barsrepresent upper and lower 95\% confidence intervals. Dashed lines represent, expected values for isometric (directly proportional) scaling of muscle properties with body mass ( $y=1.0$ : muscle mass, $y=0.67$ : PCSA, $y=0.33$ : muscle fascicle length).

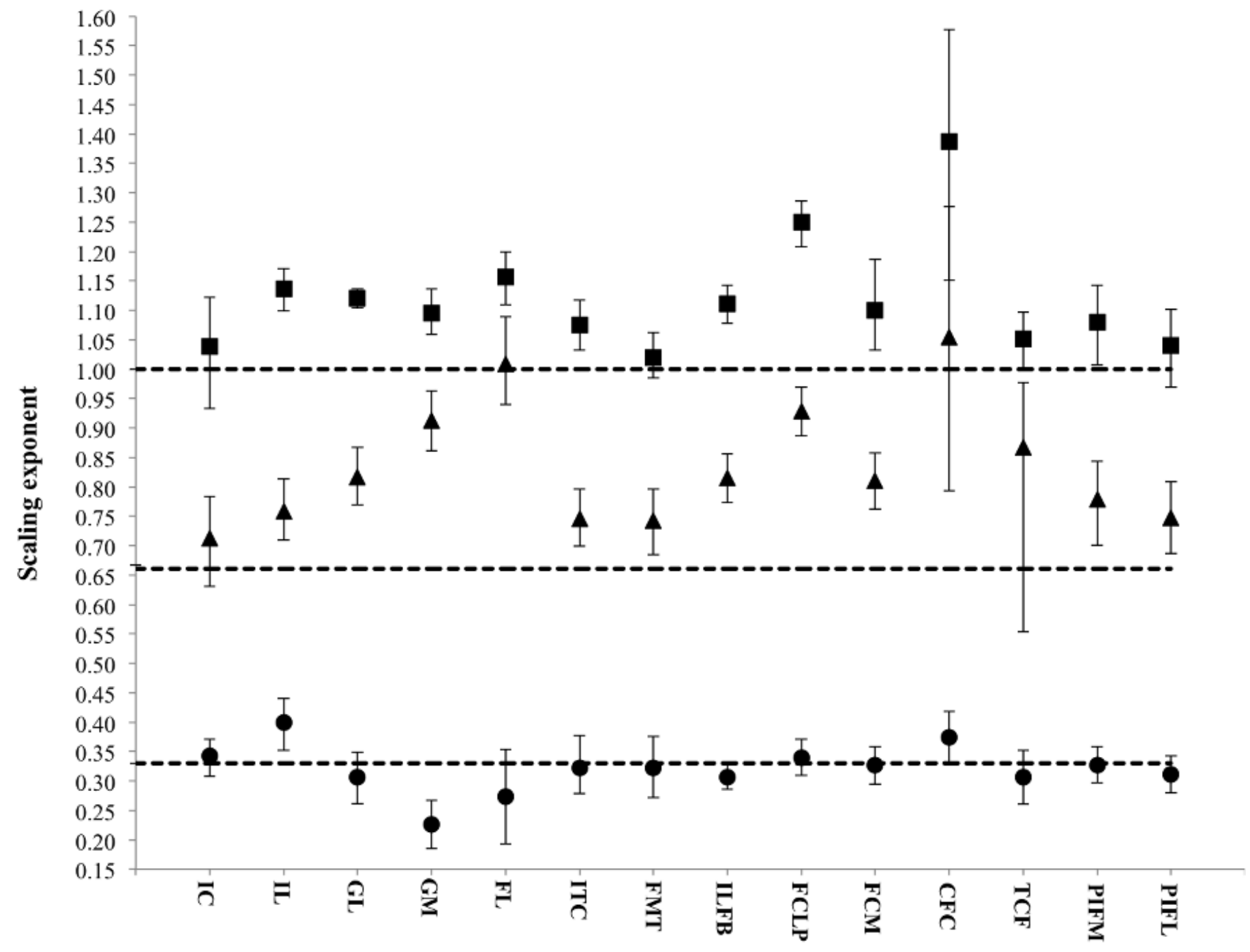

Hindlimb muscle 


\section{Figure 4}

Figure 4 - Scaling relationship of the pelvic limb bones (femur, tibiotarsus and tarsometatarsus)

95\% confidence intervals (Cls) for the femur, tibiotarsus and tarsometatarsus are $0.2947 \pm$ $0.0104,0.3086 \pm 0.0114$ and $0.3189 \pm 0.0120$ respectively (scalingexponent $\pm \mathrm{Cl}$ ). Isometric scaling of the tibiotarsus and tarsometatarsus is concluded because the $95 \%$ Cls overlapped the expected value (0.33). The femur scaled with slight negative allometry.

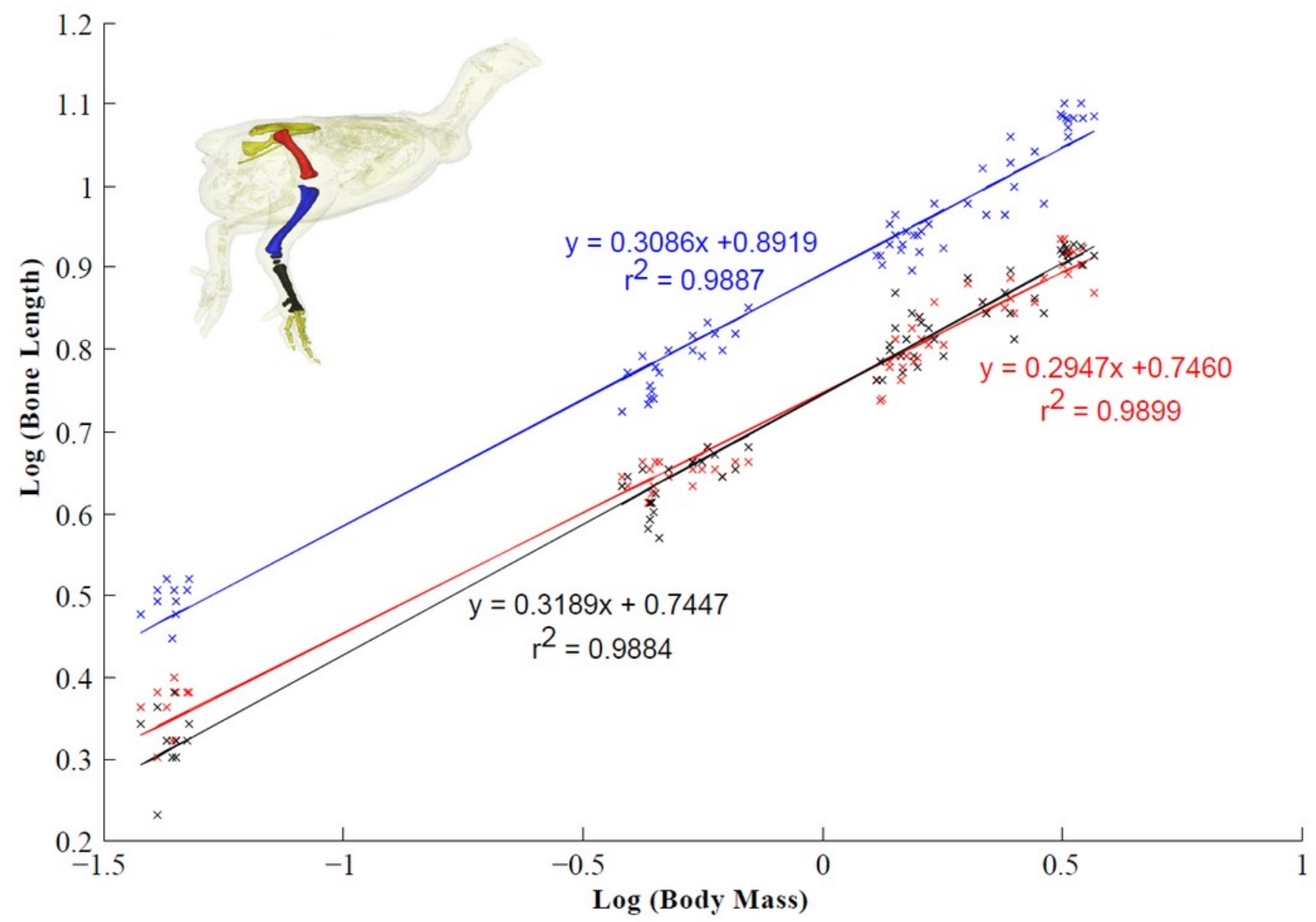




\section{Table $\mathbf{1}_{\text {(on next page) }}$}

Table 1 - Subject data

Data represented here are for the broiler chickens used only for muscle architecture and are means \pm standard deviation. These data form part of the mean data presented in Table 2 , Part I of this study. 
Table 1 - Subject data

\begin{tabular}{ccc}
\hline Age (days) & Sample size $(\mathrm{n})$ & Body mass $(\mathrm{kg})$ \\
\hline \hline 1 & 10 & $0.044 \pm 0.01$ \\
13 & 10 & $0.431 \pm 0.08$ \\
29 & 5 & $1.542 \pm 0.05$ \\
32 & 5 & $1.738 \pm 0.08$ \\
40 & 7 & $2.452 \pm 0.09$ \\
\hline
\end{tabular}

Data represented here are for the broiler chickens used only for muscle architecture and are means \pm standard deviation. These data form part of the mean data presented in Table 2, Part I of this study. 


\section{Table 2 (on next page)}

Table2 - Incidence of pathology across growth in broiler chickens

Data are presented as percentage of total study population. Bacterial chondronecrosis (BCO) and tibial dyschondroplasia (TD) were marked as present or absent. The severity of these abnormalities was not considered. Where present, valgus/ varus deformities (VVD) were classified as mild $\left(10-25^{\circ}\right)$, moderate $\left(25-45^{\circ}\right)$ or severe $\left(>45^{\circ}\right)$ following the methods described by Leterrier and Nys (1992). Tibial rotation (RT) above $20^{\circ}$ was considered abnormal. Pathologies may have been recorded in one pelvic limb or both pelvic limbs of the individual birds; this is not distinguished here. 
Table 2 - Incidence of pathology across growth in broiler chickens

\begin{tabular}{|c|c|c|c|c|c|c|c|c|}
\hline \multirow[t]{2}{*}{$\begin{array}{l}\text { Age } \\
\text { (days) }\end{array}$} & \multirow[t]{2}{*}{$\begin{array}{c}\mathrm{BCO} \\
\text { (femur) }\end{array}$} & \multirow[t]{2}{*}{$\begin{array}{c}\text { BCO } \\
\text { (tibiotar } \\
\text { sus) }\end{array}$} & \multirow[t]{2}{*}{$\begin{array}{c}\text { TD } \\
\text { (present } \\
\text { ) }\end{array}$} & VVD & \multicolumn{3}{|c|}{$\begin{array}{l}\text { RT (abnormal) } \\
\text { moderat }\end{array}$} & \\
\hline & & & & normal & mild & $\begin{array}{c}\text { ode } \\
\mathrm{e} \\
\end{array}$ & & \\
\hline 14 & 63 & 53 & 43 & 100 & 0 & 0 & 0 & 33 \\
\hline 28 & 75 & 93 & 57 & 100 & 0 & 0 & 0 & 15 \\
\hline 42 & 88 & 97 & 24 & 55 & 42 & 3 & 0 & 16 \\
\hline
\end{tabular}

Data are presented as percentage of total study population. Bacterial chondronecrosis (BCO) and tibial dyschondroplasia (TD) were marked as present or absent. The severity of these abnormalities was not considered. Where present, valgus/ varus deformities (VVD) were classified as mild $\left(10-25^{\circ}\right)$, moderate $\left(25-45^{\circ}\right)$ or severe $\left(>45^{\circ}\right)$ following the methods described by Leterrier and Nys (1992). Tibial rotation (RT) above $20^{\circ}$ was considered abnormal. Pathologies may have been recorded in one pelvic limb or both pelvic limbs of the individual birds; this is not distinguished here. 


\section{Table 3 (on next page)}

Table3 - The major muscles of the chicken pelvic limb 
Table 3 - The major muscles of the chicken pelvic limb

\begin{tabular}{lc}
\hline Muscle & Abbreviation \\
\hline \hline M. iliotibialis cranialis & IC \\
M. iliotibialis lateralis & IL \\
M. gastrocnemius pars lateralis & GL \\
M. gastrocnemius pars medialis & GM \\
M. fibularis longus & FL \\
M. iliotrochantericus caudalis & ITC \\
M. femorotibialis medialis & FMT \\
M. iliofibularis & ILFB \\
M. flexor cruris lateralis pars pelvica & FCLP \\
M. flexor cruris medialis & FCM \\
M. caudofemoralis pars caudalis & CFC \\
M. tibialis cranialis caput femorale & TCF \\
M. puboischiofemoralis pars medialis & PIFM \\
M. puboischiofemoralis pars lateralis & PIFL \\
\hline
\end{tabular}




\section{Table 4 (on next page)}

\section{Table 4 - RMA regression analyses}

Data here are the RMA regression analyses that were used to determine the linear relationships between pelvic limb muscle architecture and body mass. Expected regression slopes for isometric growth are given for each parameter. Symbols next to each calculated regression slope indicate isometric growth $(=)$, positive allometry (+; emphasized in bold) or negative allometry (-; emphasized in italics). All regressions were significant $(p<0.05)$. 
Table 4 - RMA regression analyses

\begin{tabular}{|c|c|c|c|c|c|c|c|c|c|c|c|c|c|}
\hline \multirow[t]{2}{*}{ Muscle } & \multirow{2}{*}{\begin{tabular}{|l}
$\boldsymbol{M}_{\mathbf{m}}$ \\
expected \\
slope: \\
1.00 \\
\\
Slope \\
\end{tabular}} & \multirow{2}{*}{$\begin{array}{l}\text { PCSA } \\
\text { expected } \\
\text { slope: } \\
0.67 \\
\text { Lower } \\
95 \% \text { CI } \\
\end{array}$} & \multicolumn{10}{|c|}{$\begin{array}{l}\boldsymbol{L}_{\mathbf{f}} \\
\text { expected siope: } 0.33\end{array}$} & \multirow{16}{*}{$\begin{array}{l}\text { Data here are } \\
\text { the RMA } \\
\text { regression } \\
\text { analyses that } \\
\text { were used to } \\
\text { determine the } \\
\text { linear } \\
\text { relationships } \\
\text { between } \\
\text { pelvic limb } \\
\text { muscle } \\
\text { architecture } \\
\text { and body } \\
\text { mass. }\end{array}$} \\
\hline & & & $\begin{array}{l}\text { Upper } \\
95 \% \mathrm{CI} \\
\end{array}$ & $\mathrm{R}^{2}$ & Slope & $\begin{array}{l}\text { Lower } \\
95 \% \mathrm{CI} \\
\end{array}$ & $\begin{array}{l}\text { Upper } \\
95 \% \mathrm{CI} \\
\end{array}$ & $\mathrm{R}^{2}$ & Slope & $\begin{array}{l}\text { Lower } \\
95 \% \mathrm{CI} \\
\end{array}$ & $\begin{array}{l}\text { Upper } \\
95 \% \mathrm{CI} \\
\end{array}$ & $\mathrm{R}^{2}$ & \\
\hline $\mathrm{IC}$ & $1.038(=)$ & 0.933 & 1.123 & $\sum 0.961$ & $0.712(=)$ & 0.630 & 0.783 & 0.938 & $0.342(=)$ & 0.308 & 0.372 & 0.923 & \\
\hline $\mathrm{L}$ & $1.136(+)$ & 1.099 & 1.171 & 0.994 & $0.759(+)$ & 0.709 & 0.814 & 0.968 & $0.399(+)$ & 0.352 & 0.440 & 0.938 & \\
\hline GL & $1.121(+)$ & 1.104 & 1.136 & 0.998 & $\mathbf{0 . 8 1 7}(+)$ & 0.769 & 0.868 & 0.977 & $0.306(=)$ & 0.261 & 0.349 & 0.859 & \\
\hline GM & $1.095(+)$ & 1.059 & 1.136 & $\frac{\Phi}{>} 0.992$ & $0.912(+)$ & 0.861 & 0.963 & 0.977 & $0.226(-)$ & 0.185 & 0.268 & 0.801 & \\
\hline $\mathrm{FL}$ & $1.156(+)$ & 1.109 & 1.199 & بَ 0.988 & $1.009(+)$ & 0.940 & 1.089 & 0.945 & $0.274(=)$ & 0.193 & 0.354 & 0.420 & \\
\hline $\mathrm{TC}$ & $1.075(+)$ & 1.032 & 1.118 & 0.989 & $0.746(+)$ & 0.699 & 0.796 & 0.969 & $0.322(=)$ & 0.279 & 0.377 & 0.844 & \\
\hline FMTM & $1.021(=)$ & 0.985 & 1.062 & 0.984 & $0.743(+)$ & 0.685 & 0.796 & 0.948 & $0.322(=)$ & 0.271 & 0.375 & 0.758 & \\
\hline ILFB & $1.112(+)$ & 1.078 & 1.143 & 0.994 & $0.815(+)$ & 0.773 & 0.856 & 0.981 & $0.307(=)$ & 0.286 & 0.330 & 0.961 & \\
\hline FCLP & $1.250(+)$ & 1.208 & 1.286 & 0.992 & $0.929(+)$ & 0.887 & 0.969 & 0.979 & $0.339(=)$ & 0.309 & 0.371 & 0.924 & \\
\hline FCM & $1.101(+)$ & 1.032 & 1.187 & 0.958 & $0.811(+)$ & 0.762 & 0.857 & 0.974 & $0.326(=)$ & 0.294 & 0.358 & 0.938 & \\
\hline $\mathrm{CFC}$ & $1.387(+)$ & 1.151 & 1.578 & 0.926 & $1.054(+)$ & 0.793 & 1.277 & 0.869 & $0.374(=)$ & 0.329 & 0.419 & 0.881 & \\
\hline TCF & $1.052(=)$ & 1.000 & 1.097 & 0.979 & $0.867(=)$ & 0.553 & 0.977 & 0.887 & $0.306(=)$ & 0.260 & 0.352 & 0.720 & \\
\hline PIFM & $1.079(=)$ & 1.007 & 1.143 & 0.969 & $0.779(+)$ & 0.701 & 0.843 & 0.933 & $0.327(=)$ & 0.297 & 0.358 & 0.893 & \\
\hline PIFL & $1.040(=)$ & 0.969 & 1.102 & 0.975 & $0.748(+)$ & 0.687 & 0.808 & 0.952 & $0.311(=)$ & 0.280 & 0.343 & 0.918 & \\
\hline
\end{tabular}

regression slopes for isometric growth are given for each parameter. Symbols next to each calculated regression slope indicate isometric growth $(=)$, positive allometry (+; emphasized in bold) or negative allometry (-; emphasized in italics). All regressions were significant $(\mathrm{p}<0.05)$. 


\section{Table 5 (on next page)}

Table5 - Whole body centre of mass position

Data represented are means \pm standard deviation. Centre of mass (CoM) position is calculated as a percentage of femur length and is expressed relative to the right hip joint of the chicken. Craniocaudal and dorsoventral positions are shown. Data with no common superscriptdiffer significantly at the 0.05 level. 
Table 5 - Whole body centre of mass position

\begin{tabular}{lll}
\hline \multirow{2}{*}{ Age Group } & \multicolumn{2}{l}{ CoM Position (\% femur length) } \\
& Craniocaudal & Dorsoventral \\
\cline { 2 - 3 } 14 days & $90.6 \pm 10.7^{1}$ & $\mathbf{8 9 . 8} \pm \mathbf{1 3}^{1}$ \\
28 days & $68.3 \pm 5.0^{1,2}$ & $55.4 \pm 17.7^{2}$ \\
42 days & $\mathbf{7 6 . 6} \pm \mathbf{1 2 . 2}^{2}$ & $28.2 \pm 19.5^{2}$ \\
\hline
\end{tabular}

Data represented are means \pm standard deviation. Centre of mass $(\mathrm{CoM})$ position is calculated as a percentage of femur length and is expressed relative to the right hip joint of the chicken. Craniocaudal and dorsoventral positions are shown. Data with no common superscript differ significantly at the 0.05 level. 


\section{Table 6 (on next page)}

\section{Table 6 - Pelvic limb segment inertial properties}

Data represented are means \pm standard deviation. Centre of mass position $(\mathrm{CoM})$ is located relative to the proximal end of the segment (trunk CoM is relative to the centre line between the hips), and is shown along the craniocaudal (for trunk) or proximodistal (for limbs) axis(Fig. 2). Data in a column with no common superscript differ significantly at the 0.05 level. 
Table 6 - Pelvic limb segment inertial properties

\begin{tabular}{|c|c|c|c|c|c|c|}
\hline \multirow[t]{2}{*}{ Segment } & \multirow{2}{*}{ Age Group } & \multirow{2}{*}{$\begin{array}{l}\text { Segment } \\
\text { Mass } \\
(\% \text { body } \\
\text { mass }) \\
\end{array}$} & \multirow{2}{*}{$\begin{array}{l}\text { CoM } \\
\text { Position } \\
\text { (\% segment } \\
\text { length) } \\
\end{array}$} & \multicolumn{3}{|c|}{$\begin{array}{l}\text { Radius of Gyration } \\
\text { (\% segment length) }\end{array}$} \\
\hline & & & & $\mathrm{x}$ & $\mathrm{y}$ & $\mathrm{Z}$ \\
\hline Trunk & $\begin{array}{l}14 \text { days } \\
28 \text { days } \\
42 \text { days }\end{array}$ & $\begin{array}{l}74.6 \pm 1.7^{\mathrm{a}} \\
78.0 \pm 1.8^{\mathrm{a}, \mathrm{b}} \\
81.7 \pm 3.2^{\mathrm{b}}\end{array}$ & $\begin{array}{l}19.5 \pm 2.5 \\
20.1 \pm 4.3 \\
15.3 \pm 2.7\end{array}$ & $\begin{array}{l}23.2 \pm 1.0 \\
24.0 \pm 1.2 \\
33.3 \pm 12.0\end{array}$ & $\begin{array}{l}41.1 \pm 0.3^{\mathrm{b}} \\
40.0 \pm 1.7^{\mathrm{b}} \\
\mathbf{3 7 . 1} \pm \mathbf{1 . 8}^{\mathrm{a}}\end{array}$ & $\begin{array}{l}35.0 \pm 1.9^{\mathrm{a}} \\
37.1 \pm 1.8^{\mathrm{a}, \mathrm{b}} \\
37.8 \pm 0.8^{\mathrm{b}}\end{array}$ \\
\hline Thigh & $\begin{array}{l}14 \text { days } \\
28 \text { days } \\
42 \text { days }\end{array}$ & $\begin{array}{l}5.19 \pm 1.4^{\mathrm{a}} \\
5.22 \pm 0.4^{\mathrm{a}} \\
\mathbf{8 . 2 1} \pm \mathbf{1 . 0}^{\mathrm{b}}\end{array}$ & $\begin{array}{l}43.7 \pm 4.3^{a} \\
38.1 \pm 2.0^{b} \\
28.7 \pm 2.4^{c}\end{array}$ & $\begin{array}{l}47.2 \pm 8.5 \\
48.3 \pm 6.2 \\
46.2 \pm 7.0\end{array}$ & $\begin{array}{l}44.1 \pm 7.4 \\
40.6 \pm 4.2 \\
42.5 \pm 4.3\end{array}$ & $\begin{array}{l}49.6 \pm 14.5 \\
52.1 \pm 8.8 \\
52.3 \pm 7.1\end{array}$ \\
\hline Drumstick & $\begin{array}{l}14 \text { days } \\
28 \text { days } \\
42 \text { days }\end{array}$ & $\begin{array}{l}3.9 \pm 0.3^{a} \\
4.6 \pm 0.5^{b} \\
5.66 \pm 0.2^{c}\end{array}$ & $\begin{array}{l}30.1 \pm 14.2 \\
32.7 \pm 2.3 \\
24.2 \pm 4.2\end{array}$ & $\begin{array}{l}49.1 \pm 6.3 \\
40.0 \pm 5.3 \\
34.0 \pm 12.4\end{array}$ & $\begin{array}{l}24.9 \pm 2.9 \\
25.6 \pm 4.0 \\
21.2 \pm 11.7\end{array}$ & $\begin{array}{l}\mathbf{5 1 . 0} \pm \mathbf{6 . 1} \mathbf{1}^{\mathrm{a}} \\
40.2 \pm 7.1^{\mathrm{a}, \mathrm{b}} \\
\mathbf{3 4 . 3} \pm \mathbf{1 2 . 2}^{\mathrm{b}}\end{array}$ \\
\hline Shank & $\begin{array}{l}14 \text { days } \\
28 \text { days } \\
42 \text { days }\end{array}$ & $\begin{array}{l}0.98 \pm 0.1^{\mathrm{a}} \\
1.02 \pm 0.1^{\mathrm{a}, \mathrm{b}} \\
1.23 \pm 0.2^{\mathrm{b}}\end{array}$ & $\begin{array}{l}\mathbf{3 6 . 1} \pm \mathbf{1 0 . 3}^{\mathrm{a}} \\
17.3 \pm 5.5^{\mathrm{b}} \\
22.6 \pm 6.3^{\mathrm{b}}\end{array}$ & $\begin{array}{l}50.5 \pm 1.2^{\mathrm{a}} \\
49.8 \pm 2.3^{\mathrm{a}} \\
\mathbf{3 8 . 0} \pm \mathbf{4 . 1}^{\mathrm{b}}\end{array}$ & $\begin{array}{l}18.1 \pm 0.2 \\
17.2 \pm 1.2 \\
23.3 \pm 20.7\end{array}$ & $\begin{array}{l}50.8 \pm 1.1^{\mathrm{a}} \\
50.2 \pm 2.5^{\mathrm{a}} \\
\mathbf{3 7 . 1} \pm \mathbf{2 . 7 ^ { \mathbf { b } }}\end{array}$ \\
\hline Foot & $\begin{array}{l}14 \text { days } \\
28 \text { days } \\
42 \text { days }\end{array}$ & $\begin{array}{l}0.63 \pm 0.03^{\mathrm{a}} \\
0.61 \pm 0.07^{\mathrm{a}} \\
\mathbf{0 . 9 1} \pm \mathbf{0 . 1 2}^{\mathrm{b}}\end{array}$ & $\begin{array}{l}38.6 \pm 4.3^{\mathrm{a}} \\
28.4 \pm 7.3^{\mathrm{a}} \\
\mathbf{5 1 . 9} \pm \mathbf{9 . 1}^{\mathbf{b}}\end{array}$ & $\begin{array}{l}34.3 \pm 0.9 \\
31.0 \pm 2.3 \\
38.7 \pm 16.4\end{array}$ & $\begin{array}{l}35.2 \pm 1.8^{b} \\
\mathbf{2 1 . 2} \pm \mathbf{6 . 3}^{\mathrm{a}} \\
29.9 \pm 3.9^{\mathrm{b}}\end{array}$ & $\begin{array}{l}23.3 \pm 1.4 \\
28.0 \pm 4.5 \\
29.7 \pm 21.4\end{array}$ \\
\hline
\end{tabular}

Data represented are means \pm standard deviation. Centre of mass position $(\mathrm{CoM})$ is located relative to the proximal end of the segment (trunk CoM is relative to the centre line between the hips), and is shown along the craniocaudal (for trunk) or proximodistal (for limbs) axis (Fig. 2). Data in a column with no common superscript differ significantly at the 0.05 level. 


\section{Table 7 (on next page)}

\section{Table7 - Pelvic limb bone segment dimensions}

Data presented here are for the left pelvic limb only, and are means \pm standard deviation. Total leg length is the sum of the individual pelvic limb bones. Absolute values for leg length are presented here, but normalized values(divided by body mass ${ }^{1 / 3}$ ) were used for the statistical analysis to compare how leg length changed across ontogeny (see Fig. 4 for scaling relationship). Data in a column with no common superscript differ significantly at the 0.05 level. 
Table 7 - Pelvic limb bone segment dimensions

\begin{tabular}{|c|c|c|c|c|c|}
\hline \multirow[t]{2}{*}{ Age Group } & \multirow[t]{2}{*}{ Sample size } & \multirow{2}{*}{$\begin{array}{l}\text { Leg } \\
\text { Length }(\mathrm{cm})\end{array}$} & \multicolumn{3}{|c|}{ Individual bones ( $\%$ leg length) } \\
\hline & & & Femur & Tibiotarsus & $\begin{array}{l}\text { Tarsometatar } \\
\text { sus }\end{array}$ \\
\hline 1 day & 10 & $7.5 \pm 0.44^{\mathrm{a}}$ & $30.4 \pm 0.68$ & $41.5 \pm 1.8$ & $28.0 \pm 1.4$ \\
\hline 14 days & 19 & $14.9 \pm 0.93^{b}$ & $29.9 \pm 0.6$ & $40.9 \pm 1.1$ & $29.2 \pm 1.0$ \\
\hline 28 days & 19 & $21.4 \pm 1.3^{b}$ & $29.3 \pm 1.1$ & $40.4 \pm 1.5$ & $30.2 \pm 1.1$ \\
\hline 42 days & 20 & $26.9 \pm 2.2^{b}$ & $29.0 \pm 1.1$ & $42.0 \pm 1.4$ & $29.0 \pm 0.7$ \\
\hline
\end{tabular}

Data presented here are for the left pelvic limb only, and are means \pm standard deviation.

Total leg length is the sum of the individual pelvic limb bones. Absolute values for leg length are presented here, but normalized values (divided by body mass ${ }^{1 / 3}$ ) were used for the statistical analysis to compare how leg length changed across ontogeny (see Fig. 4 for scaling relationship). Data in a column with no common superscript differ significantly at the 0.05 level. 


\section{Table 8 (on next page)}

Table8 - Levene's test and ANOVA results

Degrees of freedom $=\left(\mathrm{df}_{\text {between }}, \mathrm{df}_{\text {within }}\right)$. Where the assumption of equal variances cannot be met (significant Levene's test result), the Welch statistics are reported. 


\begin{tabular}{|c|c|c|c|c|c|}
\hline & $\begin{array}{l}\text { Levene's } \\
\text { test }\end{array}$ & $\begin{array}{l}\text { Degrees of } \\
\text { freedom }\end{array}$ & $\mathrm{F}$ & $\mathrm{P}$ & $\begin{array}{l}\text { Table } 8 \text { - } \\
\text { Levene's }\end{array}$ \\
\hline \multicolumn{5}{|l|}{ Bone lengths: } & test and \\
\hline Total Leg Length & $<0.001$ & $3,34.7$ & 968.5 & $<0.001$ & \multirow{4}{*}{$\begin{array}{l}\text { ANOVA } \\
\text { results }\end{array}$} \\
\hline Segment properties: & & & & & \\
\hline $\begin{array}{l}\text { Whole Body CoM (cranial- } \\
\text { caudal) }\end{array}$ & 0.435 & 2,12 & 6.629 & 0.011 & \\
\hline $\begin{array}{l}\text { Whole Body CoM (Dorsal- } \\
\text { ventral) }\end{array}$ & 0.475 & 2,11 & 16.729 & $<0.001$ & \\
\hline \multicolumn{5}{|l|}{ Trunk: } & \multirow{6}{*}{$\begin{array}{l}\text { Degrees of } \\
\text { freedom }= \\
\left(\mathrm{df}_{\text {between }},\right. \\
\left.\mathrm{df}_{\text {within }}\right) \text {. } \\
\text { Where the }\end{array}$} \\
\hline Mass & 0.295 & 2,12 & 11.638 & 0.002 & \\
\hline CoM position & 0.193 & 2,12 & 3.227 & 0.076 & \\
\hline Radius of gyration $(\mathrm{x})$ & $<0.001$ & $2,7.1$ & 2.088 & 0.194 & \\
\hline Radius of gyration (y) & 0.004 & $2,4.881$ & 9.732 & 0.020 & \\
\hline Radius of gyration (z) & 0.171 & 2,12 & 4.551 & 0.034 & \\
\hline \multicolumn{5}{|l|}{ Thigh: } & \multirow{6}{*}{$\begin{array}{l}\text { assumption } \\
\text { of equal } \\
\text { variances } \\
\text { cannot be }\end{array}$} \\
\hline Mass & 0.180 & 2,12 & 13.65 & 0.001 & \\
\hline CoM position & 0.547 & 2,12 & 30.675 & $<0.001$ & \\
\hline Radius of gyration $(\mathrm{x})$ & 0.555 & 2,11 & 0.108 & 0.899 & \\
\hline Radius of gyration (y) & 0.508 & 2,12 & 0.514 & 0.611 & \\
\hline Radius of gyration (z) & 0.103 & 2,12 & 0.099 & 0.907 & \\
\hline \multicolumn{5}{|l|}{ Drumstick: } & \multirow{6}{*}{$\begin{array}{l}\text { met } \\
\text { (significant } \\
\text { Levene's test } \\
\text { result), the } \\
\text { Welch }\end{array}$} \\
\hline Mass & 0.002 & $2,6.885$ & 69.702 & $<0.001$ & \\
\hline CoM position & 0.054 & 2,12 & 1.261 & 0.318 & \\
\hline Radius of gyration (x) & 0.358 & 2,12 & 3.902 & 0.050 & \\
\hline Radius of gyration (y) & 0.270 & 2,12 & 1.024 & 0.388 & \\
\hline Radius of gyration (z) & 0.441 & 2,12 & 4.533 & 0.034 & \\
\hline \multicolumn{5}{|l|}{ Shank: } & \multirow{12}{*}{$\begin{array}{l}\text { statistics are } \\
\text { reported. }\end{array}$} \\
\hline Mass & 0.583 & 2,12 & 4.820 & 0.029 & \\
\hline CoM position & 0.503 & 2,12 & 7.985 & 0.006 & \\
\hline Radius of gyration $(\mathrm{x})$ & 0.129 & 2,12 & 31.746 & $<0.001$ & \\
\hline Radius of gyration (y) & 0.012 & $2,5.542$ & 1.297 & 0.695 & \\
\hline Radius of gyration (z) & 0.301 & 2,12 & 59.342 & $<0.001$ & \\
\hline \multicolumn{5}{|l|}{ Foot: } & \\
\hline Mass & 0.295 & 2,12 & 18.969 & $<0.001$ & \\
\hline CoM position & 0.502 & 2,12 & 13.332 & 0.001 & \\
\hline Radius of gyration $(\mathrm{x})$ & 0.027 & $2,6.047$ & 4.376 & 0.465 & \\
\hline Radius of gyration (y) & 0.189 & 2,12 & 1.920 & 0.001 & \\
\hline Radius of gyration (z) & 0.027 & $2,5.831$ & 2.367 & 0.717 & \\
\hline
\end{tabular}

